\title{
Return to pivoting sport after $A C L$ reconstruction: association with osteoarthritis and knee function at the 15-year follow-up
}

\author{
Britt Elin Øiestad, ${ }^{1}$ Inger Holm, ${ }^{2,3}$ May Arna Risberg ${ }^{2,4}$
}

\begin{abstract}
'Department of Physiotherapy, Oslo Metropolitan University,

Oslo, Norway

${ }^{2}$ Division of Orthopedic Surgery, Oslo University Hospital, Oslo, Norway

${ }^{3}$ Faculty of Medicine, Institute of Health and Society, University of Oslo, Oslo, Norway

${ }^{4}$ Department of Sport Medicine, Norwegian School of Sport

Sciences, Oslo, Norway
\end{abstract}

\section{Correspondence to}

Dr Britt Elin Øiestad,

Department of Physiotherapy,

Oslo Metropolitan University,

Oslo 0130, Norway;

britt-elin.0iestad@hioa.no

Accepted 2 March 2018

Published Online First

17 March 2018

ABSTRACT

Objectives To examine the associations between return to pivoting sport following $A C L$ reconstruction $(A C L R)$ and knee osteoarthritis (OA), and self-reported knee symptoms, function and quality of life after 15 years.

Methods Study sample included 258 participants with ACLR 15 years previously. Return to pivoting sport (handball, soccer and basketball) data were collected by interviews, and symptomatic OA was defined as Kellgren and Lawrence grade $\geq 2$ plus almost daily knee pain in the last month. Self-reported symptoms, function and quality of life were assessed with the Knee Injury and Osteoarthritis Outcome Score. Adjusted regression models were used to analyse the associations between return to pivoting sport and $\mathrm{OA}$ (present or not), and self-reported outcomes. P values $\leq 0.05$ were considered statistically significant.

Results Two hundred and ten (81\%) participants (57\% men) with a mean age of $39.1( \pm 8.7)$ years completed the 15-year follow-up, and 109 (52\%) had returned to pivoting sport. Returning to pivoting sport was associated with less symptomatic OA $(O R \quad 0.28,95 \% \mathrm{Cl}$ 0.09 to 0.89 ) and radiographic $\mathrm{OA}(\mathrm{OR} 0.40,95 \% \mathrm{Cl}$ 0.17 to 0.98 ), adjusted for age, sex, combined injury, self-reported knee function, and time between injury and surgery. Those who returned to pivoting sport had better function in activities of daily living (ADL).

Conclusion The participants with ACLR who returned to pivoting sport had lower odds of knee OA and better self-reported ADL function. Further investigation is required to understand the clinical significance of these findings.

\section{INTRODUCTION}

The prevalence of knee osteoarthritis (OA) is alarmingly high in middle-aged individuals with an ACL tear. ${ }^{1-3}$ The pathogenesis of the post-traumatic degenerative disease process is unclear, with many factors likely to contribute immediately after the ACL tear. ${ }^{45}$ Intra-articular damage to the cartilage, menisci and subchondral bone, and inflammatory responses following a high-impact knee injury, may initiate a degenerative process. ${ }^{67}$ Medial meniscal injury suffered along with the ACL tear, or later, is the only well-documented risk factor for knee OA. ${ }^{8}$ Conflicting evidence exists on the influence of high body mass index (BMI), a long time period between injury and surgery, ${ }^{8}$ and muscle weakness. ${ }^{9}{ }^{10}$

The association between return to sport following 2018:52:1199-1204.

loading on the knees, and a higher prevalence of knee OA has been reported in uninjured soccer players compared with a matched group of military personnel. ${ }^{12}$ Returning to pivoting sport following an ACL tear with poor knee function may predispose for future knee OA. ${ }^{13}$

There is low-quality evidence to support a relationship between sport participation and $\mathrm{OA}$ in elite individuals with ACL tear, based on recent systematic reviews and meta-analyses. ${ }^{8} 1415 \mathrm{ACL}$ reconstruction (ACLR) individuals who return to sport seem to have better self-reported knee function compared with those who do not return, ${ }^{16}$ but conflicting results have been published. ${ }^{17}$

The primary aim of this study was to examine the association between returning to pivoting sport following ACLR and knee OA at 15 years postACLR. The secondary aim was to assess the association between returning to pivoting sport and self-reported knee symptoms, function and quality of life at 15 years post-ACLR. We hypothesised that participants who returned to pivoting sport following ACLR had a higher prevalence of knee OA than those who did not return to pivoting sport.

\section{MATERIALS AND METHODS}

\section{Study design and participants}

This is a secondary analysis using data from a prospective cohort study of 258 men and women who had an ACLR at four different hospitals in Oslo, Norway, in the period between 1990 and 1997. The participants were consecutively included in four projects (two randomised controlled trials and two cohort studies) after they were scheduled for reconstructive surgery. The four projects had the same inclusion and exclusion criteria, but with different objectives, including differences in surgical graft types, surgical methods and functional outcomes. ${ }^{18-21}$ Longitudinal results of knee function and knee OA have previously been published. ${ }^{22-24}$

The inclusion criteria for the study were men and women between 15 and 50 years, and an arthroscopically verified ACL tear. The participants had either an ACL tear in isolation, or in combination with other injuries such as collateral ligament tears, meniscus injuries and/or cartilage injuries. Individuals with other major injuries to the lower extremities that were suffered less than 1 year before surgery, and posterior cruciate ligament injury or contralateral ACL tear were excluded. often occur during participation in pivoting sports, such as soccer. ${ }^{11}$ Pivoting sports cause high-impact 


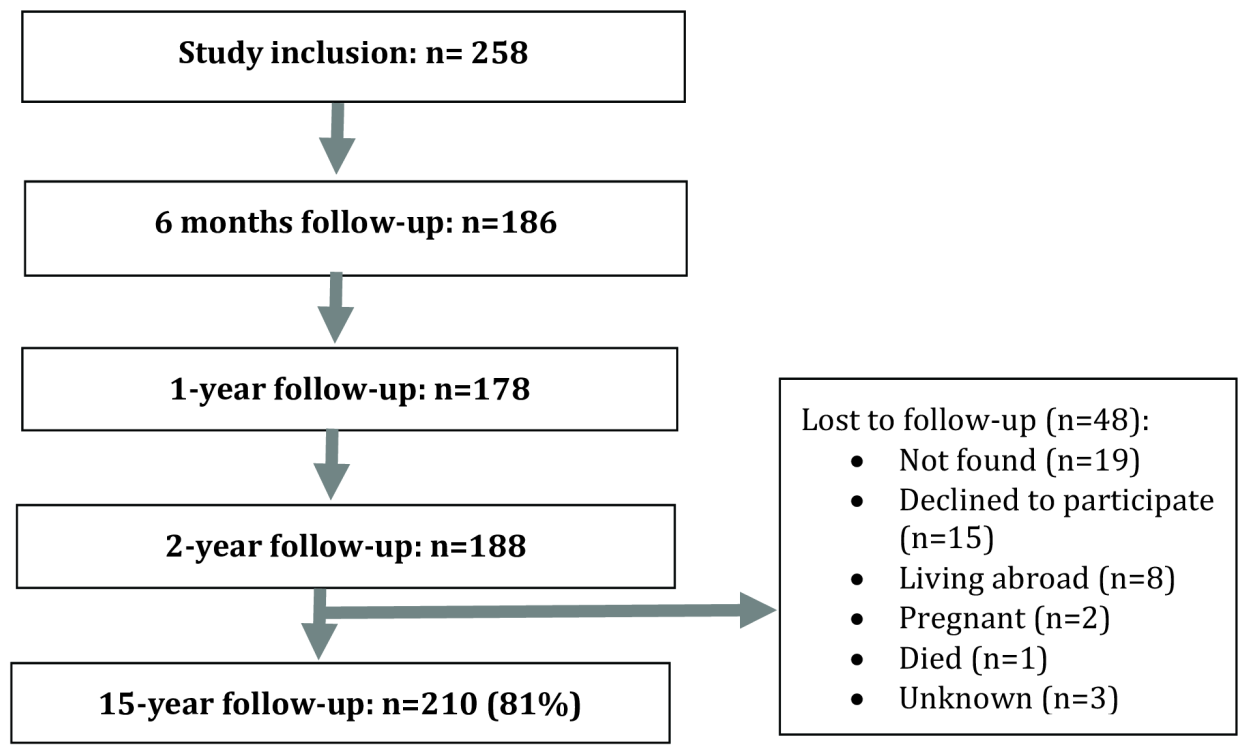

Figure 1 Flow chart of the study participants.

\section{Study setting and ethical considerations}

The same research team with physiotherapists and orthopaedic surgeons conducted all clinical and functional assessments at Oslo University Hospital at 6 months, 1, 2 and 15 years postACLR (figure 1).

The study participants signed an informed consent at the 15 -year follow-up.

\section{Surgical procedure and rehabilitation}

The surgical procedures are described in previous published studies and included reconstruction of the torn ACL using bone-patellar-tendon-bone autograft in 221 participants $^{25}$ and hamstrings tendon autograft in 37 participants. ${ }^{18}$ All the participants went through a structured, individualised rehabilitation programme, with exercises targeting dynamic stability and increasing quadriceps and hamstrings muscle strength. ${ }^{22}$

\section{Assessment of return to pivoting sport}

Pivoting sport was defined as level I sports according to Hefti et $a l,{ }^{26}$ and included soccer, handball, basketball, tennis and other ball games with rapid start and stop movements.

Information on return to pivoting sport was collected by interviewing each study participant at the 15 -year follow-up. The following questions were asked: (1) Did you return to pivoting sport following ACLR? (yes/no); (2) What pivoting sport did you return to? (open question); (3) How many months postACLR did you participate in your first competitive game?; (4) What was the highest level of sport you returned to after ACLR (elite or recreational, both may include competitive games); (5) How many months/years did you participate in pivoting sport following ACLR? Furthermore, there were questions about why participants did not return to their preinjury level and the reasons for not returning to pivoting sports following ACLR. Data from question 1 were used as independent variable in the analyses. To evaluate the validity of the return to pivoting sport data, we compared data from question 1 with the Tegner Activity Scale (0-10) data collected for the first 120 included participants at 2 years post-ACLR.

\section{Outcomes}

At the 15-year follow-up, radiographic examination of the tibiofemoral joint was conducted bilaterally using a frame to standardised standing position (SynaFlexer frame from Synarc, California, USA). The frame ensures approximately $20^{\circ}$ flexion in the knee joints and $5^{\circ}$ external rotation of the feet. This position has been shown to be reliable for measurement of joint space width. ${ }^{27}$ Our senior musculoskeletal radiologist read all the radiographs according to the Kellgren and Lawrence (KL) classification system (0-4). Radiographic OA was diagnosed as grade 2 (osteophytes and possible joint space narrowing) or higher, defined as $\mathrm{KL} \geq 2$. We have previously published interrater and intrarater reliability results for the radiologist and one orthopaedic surgeon. ${ }^{23}$ They read and scored 35 radiographs from the cohort twice with a 4 -week interval. Intrarater reliability showed a kappa value of 0.7 , and inter-rater reliability showed a kappa value of 0.57 . Symptomatic knee OA was diagnosed as $\mathrm{KL} \geq 2$ and knee pain almost every day the last month. ${ }^{28}$

Self-reported knee function was assessed with the Knee injury and Osteoarthritis Outcome Score (KOOS) at the 15-year follow-up. ${ }^{29}$ KOOS includes five subscales: pain, other symptoms (Symptoms), function in daily living (activities of daily living (ADL)), function in sport and recreation (Sport/Rec), and knee-related quality of life (QoL). Each subscale was converted to a $0-100$ score, where 0 indicated worst possible score and 100 indicated best possible score, according to the recommendations posted at www.koos.nu.

\section{Covariates}

Covariates of knee function were included in the analyses because we believed that those with better function early postACLR would be more likely to return to pivoting sport. The Cincinnati Knee Score ${ }^{30}$ was included in the prospective study to measure self-reported knee function. Isokinetic knee extensor and flexor muscle strength tests (Cybex 6000 machine, Cybex Lumex) were assessed at all the follow-ups. ${ }^{23}$ The isokinetic strength tests were conducted using the following procedure: the participants warmed up for $6-8 \mathrm{~min}$ on a stationary bike. Then, 
five maximal isokinetic repetitions at $60^{\circ} / \mathrm{s}$ and a $0^{\circ}-90^{\circ}$ range of motion of the knee joint were performed. Data were presented as total work of the five knee extension/flexion repetitions in Joules (J) divided by body weight (BW). The Tegner Activity Scale ${ }^{31}$ was assessed preoperatively and at the 2-year follow-up for the first 120 participants.

Height (in metres) and BW (in kilograms) were measured, and BMI calculated by kilogram/(metres $\left.{ }^{2}\right)$. Additional knee injuries suffered at the time of the ACL tear or during follow-up (in this study referred to as combined injuries), or ACL graft tears, were recorded by asking the participants at the 15 -year follow-up if they had had any new knee injuries or surgeries. To verify this information, we read the individual surgical files and medical records. Data on combined injuries and ACL graft tears included all injuries up to the 15 -year follow-up.

\section{Statistical analyses}

Descriptive statistics were presented as number (n) and percentages (\%) for categorical variables, as median (range) for non-normally distributed continuous variables, and as mean and SD for normally distributed variables. Shapiro-Wilk test was used to analyse normality of the variables. Analysis for assessing the validity of the retrospectively collected return to pivoting sport data was conducted as follows: Tegner Activity Scale data from 2 years post-ACLR were dichotomised into score $\geq 6$ (pivoting sport) vs $<6$ (no pivoting sport), and associated to the return to sport rate (question 1) with Pearson's $\mathrm{X}^{2}$ test. We anticipated that those who wanted to return to pivoting sports had done so by 2 years post-ACLR.

To analyse the aims of the study, we used adjusted regression models. The associations between symptomatic and radiographic knee OA (present or not) at the 15-year follow-up (dependent variables) and return to pivoting sport (independent variable) were analysed by logistic regression analyses. Possible confounding factors for these associations were included on the basis of previous analyses on this cohort, ${ }^{9}$ which identified age and meniscal injuries as risk factors for radiographic knee $\mathrm{OA}$ and poor knee function post-ACL for symptomatic knee OA. In addition, the covariates were included on the basis of group comparisons between those who returned versus those who did not return to pivoting sport by Pearson's $\chi^{2}$ tests, Student's t-tests or Mann-Whitney U tests. Based on these analyses, the covariates were sex, self-reported knee function at 6 months post-ACLR, and time between injury and surgery. Linear regression models were used for all the five KOOS subscales (dependent variables) and return to pivoting sport (independent variable). Multicollinearity was not found between the covariates, assessed by correlation analyses. Other assumptions for linear regression analysis were considered not violated, because the independent variable of interest (return to sport) was dichotomised. Possible confounding factors were considered to be age, sex, combined injury and self-reported knee function at 6 months post-ACLR.

Group comparisons with non-parametric tests were conducted for age, sex and the Cincinnati Knee Score at 6 months postACLR between those who dropped out of the 15-year follow-up $(n=48)$ versus those who met $(n=210)$.

Results with $\mathrm{P}$ values of $\leq 0.05$ were considered to be statistically significant.

\section{RESULTS}

Of the 258 participants in the prospective cohort, $210(81 \%)$ provided data at the 15 -year follow-up (figure 1 ). There were
Table 1 Return to pivoting sport data from the 15-year follow-up $(n=210)$

\begin{tabular}{ll}
\hline & $\mathrm{n}(\%)$ \\
\hline Returned to pivoting sports & $109(52)$ \\
\hline Yes & $101(48)$ \\
\hline No & \\
\hline If yes ( $\mathrm{n}=109)$ & \\
\hline Type of pivoting sport? & $31(29)$ \\
\hline Handball & $59(54)$ \\
\hline Soccer & $8(7)$ \\
\hline Basketball & $10(9)$ \\
\hline Other ball games & 1 \\
\hline Missing & \\
\hline Did you return to the same activity level of pivoting sport? & $39(36)$ \\
\hline No & $56(51)$ \\
\hline Yes & $14(13)$ \\
\hline Missing/unknown & \\
\hline If no ( $\mathrm{n}=101$ ) & \\
\hline Why did you not return to pivoting sport? & $60(59)$ \\
\hline Due to symptoms from the ACLR knee & $41(41)$ \\
\hline Other reasons than the ACLR knee & $(\mathrm{n}=40)$ \\
\hline Returned to other activities? & 31 \\
\hline Alpine skiing* & 2 \\
\hline Running & 2 \\
\hline Dancing & 3 \\
\hline Karate & 2 \\
\hline Other & \\
\hline
\end{tabular}

*15 subjects returned to both a pivoting sport and alpine skiing and are categorised as pivoting sport.

$A C L R, A C L$ reconstruction.

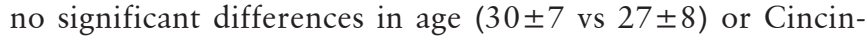
nati Knee Score at 6 months $(77 \pm 13$ vs $74 \pm 15)$ between those who provided data at the 15 -year follow-up and those who did not. Participants had been injured while participating in soccer $(n=70,33 \%)$, handball $(n=37,18 \%)$ or alpine skiing $(n=45,21 \%)$. The combined injuries $(61 \%)$ consisted of meniscus injuries in 84 participants (40\%), meniscus injury in combination with collateral injury in $5(2 \%)$, a combination of meniscus injury, collateral ligament injury and chondral lesion in $3(2 \%)$, meniscus injury and chondral lesion in 29 (14\%), and chondral lesion only in 7 (3\%) study participants. ${ }^{32}$ Ten $(8 \%)$ of the total 128 participants with additional injury suffered the injury in the period between ACLR and the 15 -year follow-up.

Overall, 71\% $(n=149)$ returned to some type of sports following the ACLR, but only 52\% $(n=109)$ returned to pivoting sports (table 1 ). Of those who returned to pivoting sports, 51\% reported that they returned to their preinjury sport. The median (range) time before participating in competitive play following ACLR was 10.5 (4-120) months. The median (range) duration participating at the same level for those who returned to pivoting sport was $42(0.5-144)$ months $(n=61$, missing data for $n=48)$. Of those who did not return to pivoting sport, $59 \%$ reported it was because of symptoms from their ACLR knee.

There was a statistically significant association between Tegner Activity Scale at 2 years and the rate of return to pivoting sport (Pearson's $\chi^{2}: 22.03 ; \mathrm{P}<0.000$ ) (table 2). Participants with ACLR who returned to pivoting sport were younger, had shorter time between injury and surgery, and had better self-reported knee 


\begin{tabular}{|c|c|c|}
\hline Variables & $\begin{array}{l}\text { Pivoting sport } \\
(\mathrm{n}=109)\end{array}$ & $\begin{array}{l}\text { Not pivoting sport } \\
(n=101)\end{array}$ \\
\hline $\begin{array}{l}\text { Median (range) age at surgery, } \\
\text { years }\end{array}$ & $24.6(13-48)^{*}$ & $27.1(13-61)^{*}$ \\
\hline $\begin{array}{l}\text { Median (range) BMI at 6-month } \\
\text { FU }\end{array}$ & $23.2(15.7-33.9)$ & $23.3(16.2-30.4)$ \\
\hline Mean (SD) BMI at 15-year FU & $26.1(3.5)$ & $26.5(3.8)$ \\
\hline Female, n (\%) & $46(51)$ & $45(49)$ \\
\hline Male, n (\%) & $63(52)$ & $56(48)$ \\
\hline $\begin{array}{l}\text { Isolated injury up to } 15 \text {-year FU, } \\
\mathrm{n}(\%)\end{array}$ & $49(60)$ & $33(40)$ \\
\hline $\begin{array}{l}\text { Combined injury up to } 15 \text {-year } \\
\text { FU, } n(\%)\end{array}$ & $60(46)$ & $68(54)$ \\
\hline Unilateral ACL tear, $\mathrm{n}(\%)$ & $85(52)$ & $79(48)$ \\
\hline Bilateral ACL tear, $\mathrm{n}(\%)$ & $24(52)$ & $22(48)$ \\
\hline Reinjury up to 15 -year FU (\%) & $24(57)$ & $18(43)$ \\
\hline No reinjury up to 15 -year FU (\%)† & $84(50)$ & $83(50)$ \\
\hline Hamstrings graft, n (\%) & $16(55)$ & $13(45)$ \\
\hline Patellar tendon graft, $\mathrm{n}(\%)$ & $93(51)$ & $89(49)$ \\
\hline $\begin{array}{l}\text { Median (range) months injury to } \\
\text { surgery ( } n=195)\end{array}$ & $5(0-260)^{*}$ & $9(0-278)^{*}$ \\
\hline $\begin{array}{l}\text { Median (range) Cincinnati at } \\
6 \text {-month FU }\end{array}$ & $82(36-100)^{*}$ & $74(44-100)^{*}$ \\
\hline $\begin{array}{l}\text { Median (range) Cincinnati at } \\
\text { 1-year FU }\end{array}$ & $88(60-100)$ & $84.5(41-100)$ \\
\hline $\begin{array}{l}\text { Median (range) Cincinnati at } \\
\text { 2-year FU }\end{array}$ & $89(57-100)$ & $90(37-100)$ \\
\hline $\begin{array}{l}\text { Mean (SD) quads strength J/BW at } \\
6 \text {-month FU }\end{array}$ & $8.6(2.9)$ & $8.2(2.8)$ \\
\hline $\begin{array}{l}\text { Mean (SD) quads strength J/BW } \\
\text { at 1-year FU }\end{array}$ & $10.4(2.2)$ & $9.9(2.3)$ \\
\hline $\begin{array}{l}\text { Mean (SD) quads strength J/BW } \\
\text { at 2-year FU }\end{array}$ & $11.1(1.9)$ & $10.6(2.2)$ \\
\hline Tegner preinjury $(<6), \mathrm{n}(\%) \ddagger$ & $3(14)^{*}$ & $18(86)^{*}$ \\
\hline Tegner preinjury ( $\geq 6), n(\%) \ddagger$ & $39(51)$ & $38(49)$ \\
\hline Tegner at 2-year FU $(<6), \mathrm{n}(\%) \ddagger$ & $13(32)^{*}$ & $45(79)^{*}$ \\
\hline Tegner at 2-year FU $(\geq 6), n(\%) \ddagger$ & $28(68)$ & $12(21)$ \\
\hline \multicolumn{3}{|c|}{$\begin{array}{l}{ }^{*} \mathrm{P}<0.05 \text {. } \\
\mathrm{tn}=1 \text { missing data for reinjuries. } \\
\ddagger \text { Total } n=98 \text {. Reinjuries consisted of ACL graft tears ( } \mathrm{n}=18) \text { and meniscal reinjuries } \\
\text { ( } \mathrm{n}=24) \text {. The categorical variables were analysed with Pearson's } \mathrm{X}^{2} \text { test (sex, isolated } \\
\text { vs combined injury, unilateral vs bilateral injury, reinjury vs no reinjury, and graft } \\
\text { type). } \\
\text { BMl, body mass index; BW, body weight; FU, follow-up; J, Joules. }\end{array}$} \\
\hline
\end{tabular}

Table 4 Return to pivoting sport and self-reported knee function at the 15-year follow-up

\begin{tabular}{lll}
\hline Variables & Beta $(95 \% \mathrm{Cl})$ & P values \\
\hline Returned to pivoting sport $(\mathrm{n}=164)$ & & \\
KOOS pain & $4.1(-0.09$ to 8.33$)$ & 0.055 \\
KOOS symptoms & $3.0(-1.89$ to 7.8$)$ & 0.228 \\
KOOS ADL & $3.4(0.29$ to 6.5$)$ & 0.032 \\
KOOS sport/recreation & $6.6(-0.45$ to 13.7$)$ & 0.067 \\
\hline KOOS QoL & $4.5(-2.1$ to 11$)$ & 0.175
\end{tabular}

Each subscore was adjusted for age, sex, combined injury up to 15 years, Cincinnati Knee Score at 6 months, and time between injury and surgery.

$A D L$, activities of daily living; KOOS, Knee injury and Osteoarthritis Outcome Score; QoL, quality of life.

function at the 6-month follow-up compared with those who did not return to pivoting sport (table 2).

\section{Association between return to pivoting sport and knee $\mathrm{OA}$}

Symptomatic OA was found in 31 participants (15\%) and radiographic $\mathrm{OA}$ was detected in 62 participants $(30 \%)$ at the 15 -year follow-up. Of the 109 participants who returned to pivoting sports, $6(5.5 \%)$ had symptomatic OA and $20(18.5 \%)$ had radiographic OA. Of those who did not return to pivoting sport $(\mathrm{n}=101), 25$ (25\%) had symptomatic OA and 42 (42\%) had radiographic OA. The participants who returned to pivoting sports had lower odds of symptomatic $\mathrm{OA}(0.28,95 \% \mathrm{CI} 0.09$ to 0.89$)$ and radiographic OA $(0.40,95 \% \mathrm{CI} 0.17$ to 0.98$)$ at 15 years compared with those who did not return to pivoting sport (table 3 ).

\section{Association between return to pivoting sport and self- reported outcomes}

Participants who returned to pivoting sport had significantly better KOOS ADL compared with those who did not return to pivoting sport adjusted for covariates (table 4). No statistically significant associations were found between return to pivoting sport and the other KOOS subscales. Figure 2 shows the KOOS profiles for the group that returned to pivoting sport versus the group that did not return to pivoting sport.

\section{DISCUSSION}

Our hypothesis that participants who returned to pivoting sport following ACLR had more symptomatic OA at 15 years post-ACLR was not supported. In fact, the participants who returned to pivoting sport had significantly lower odds of symptomatic and radiographic

Table 3 Multivariate model of return to pivoting sport and knee OA at the 15-year follow-up ( $n=164)$

\begin{tabular}{|c|c|c|c|c|c|c|}
\hline \multirow{2}{*}{$\begin{array}{l}\text { Dependent variables } \\
\text { Independent variables }\end{array}$} & \multicolumn{3}{|c|}{ Symptomatic $O A(K L \geq 2)$} & \multicolumn{3}{|c|}{ Radiographic $O A(K L \geq 2)$} \\
\hline & OR & $95 \% \mathrm{Cl}$ & $P$ values & OR & $95 \% \mathrm{Cl}$ & $P$ values \\
\hline Returned to pivoting sport $(n=85)$ & 0.28 & 0.09 to 0.89 & 0.031 & 0.40 & 0.17 to 0.98 & 0.045 \\
\hline Sex & 1.23 & 0.42 to 3.66 & 0.698 & 1.97 & 0.79 to 4.92 & 0.147 \\
\hline Combined injury up to 15 years & 13.4 & 1.7 to 107 & 0.008 & 7.49 & 2.29 to 24.5 & 0.001 \\
\hline Self-reported knee function at 6 months* & 1.03 & 0.99 to 1.06 & 0.126 & 1.04 & 0.99 to 1.07 & 0.056 \\
\hline
\end{tabular}

Covariates in the multivariate model were age, sex, combined injury, self-reported knee function, and time between injury and surgery. Reference groups: not returning to pivoting sport; women, having isolated injury.

${ }^{*}$ Cincinnati Knee Score (0-100).

$\mathrm{KL}$, Kellgren and Lawrence; OA, osteoarthritis. 


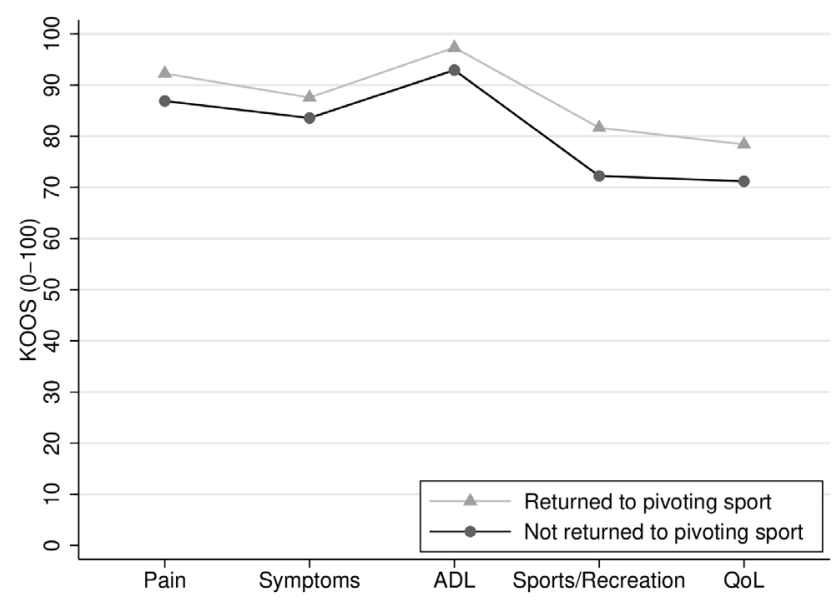

Figure 2 Knee injury and Osteoarthritis Outcome Score (KOOS) profile for the group that returned to pivoting sport versus the group that did not return. ADL, activities of daily living; QoL, quality of life.

OA and better self-reported ADL function. However, the clinical relevance of the 3.4 points greater KOOS-ADL score in the return to pivoting sport group is questionable.

\section{Association between return to pivoting sport and $\mathrm{OA}$}

Those who returned to pivoting sport had less symptomatic and radiographic knee OA than those who did not return. The causal factors for this are unknown. The participants who returned to pivoting sport may have had a less serious injury with less intra-articular damage than the participants who did not return to pivoting sport, but no data including intra-articular damage to the bone marrow or subchondral bone, or inflammatory markers, were available. Those who returned to pivoting sport may also have had a combination of beneficial factors making them well prepared to return to pivoting sport. Because $59 \%$ of those who did not return reported that this was because of poor knee function, this group may have lacked the required functional level to return and sustain good knee health over time. In addition, $30 \%$ of those who did not return to pivoting sport returned to alpine skiing, considered as a level II sport, but still knee-demanding.

Many ACLR athletes who desire to return to sport ${ }^{33}$ lack motivation during the rehabilitation phases, which can affect knee function at the time when others return to sport. Ardern $e t a b^{34}$ reported from a follow-up study of 2-7 years of ACLR individuals that $61 \%$ had returned to their preinjury level and $41 \%$ had participated in competitive sport at some time after surgery. In line with our results, Ardern et al found that younger people were more likely to have returned to their preinjury sport compared with older individuals. Other literature has shown that men below 25 years of age and those being psychologically ready to go back to sports have a higher likelihood of returning. ${ }^{35}$ Both physical and psychological factors seem to influence the return to competitive sport after ACLR. ${ }^{163637}$

The current study indicates that returning to pivoting sports with a good self-reported knee function does not increase the longterm development of knee OA. However, our study participants demonstrated decreased activity level from preinjury to the 2-year follow-up (according to Tegner activity data in table 2), indicating that they may have changed to activities that are more beneficial for future knee joint health, such as cycling. More emphasis on adequate rehabilitation including optimal knee function for all ACLR patients is warranted to prevent development of OA. ${ }^{38}$

\section{Association between return to pivoting sport and knee function at 15 years}

The self-reported KOOS ADL was statistically significantly better in the group that returned to pivoting sport than in the group that did not return to pivoting sport. However, the betweengroup difference was only 3.4 points on the KOOS subscale and is probably clinically meaningless. Even though larger group differences were seen for the other KOOS subscale values, the CIs were wider than for KOOS ADL, which may explain the lack of statistically significant differences. Filbay $e t a l^{39}$ reported that subjects who returned to competitive sport at the same or higher level had 12 points higher knee-related quality of life score compared with those who did not return to sport 5-20 years after the ACLR. The greater difference observed by Filbay et al may relate to their inclusion of ACLR patients with knee pain and symptoms, and with shorter follow-up time, which would result in a different sample from the present study.

\section{Study strengths and limitations}

This study includes a set of prospectively collected data with only $19 \%$ loss to follow-up in a cohort of ACLR participants over 15 years. In the multivariate regression models, 164 study participants were included due to missing data for the variables 'time between injury and surgery' and 'the Cincinnati knee score at 6 months post-ACLR'. The results did not change when we reanalysed the data without these variables, thus increasing the numbers. Imputation was not conducted because the groups did not differ for age and sex, and the missing data seemed to be related to random factors, such as not found, declined to participate (mostly due to busy schedule) and living abroad (figure 1).

Although we collected data on return to pivoting sport retrospectively, these data provide a valuable contribution to the literature. While the return to pivoting sport data seem valid compared with the prospectively collected Tegner data at 2 years, recall bias may have influenced the results. Also, we did not define alpine skiing as a pivoting sport, but the Tegner score 6 originally included both pivoting sports and alpine skiing. Thus, we repeated the analysis without the study participants who returned to alpine skiing, but this did not alter the statistically significant association between Tegner at 2 years and the return to pivoting sport data from the 15 -year follow-up.

Return to sport is a difficult topic as it represents at least three main components: return to participation (return to play), return to sport (type of sport/preinjury sport) and return to performance level (preinjury sport and level) ${ }^{40}$ Elite athletes are more than twice as likely to return to preinjury sport than recreational athletes ${ }^{41}$ and a new meta-analysis showed that $83 \%$ of elite athletes returned to preinjury sport after ACLR. ${ }^{15}$ In our study we did not use the broad term return to sport. We used return to pivoting sports defined as level I sports according to Hefti $e t a l^{26}$ and Grindem et $a l^{42}$ including soccer, handball, basketball, tennis and other ball games with rapid start and stop movements. We had no data on performance level, or exercise frequency, intensity and duration during the follow-up period, factors that might have influenced knee joint health at the 15 -year follow-up. Furthermore, we had no data on psychological factors, such as fear of reinjury and lack of confidence, which have been shown to influence the return to sport rate. ${ }^{43}$ Finally, this study is a secondary analysis of data from the prospective cohort study, which limits the internal validity of the study. In addition, multiple comparisons in our analyses may have given spurious significant associations. Thus, interpretations should be drawn with caution. 


\section{CONCLUSION}

The participants with ACLR who returned to pivoting sport had lower odds of symptomatic and radiographic OA, and a small but possibly clinically meaningless difference in function related to ADL. Further investigation is required to understand the clinical significance of these findings.

Acknowledgements We would like to thank radiologist Ragnhild Gunderson at Oslo University Hospital for grading all the radiographs.

Funding The 15-year follow-up study was funded by the South-Eastern Norway Regional Health Authority.

\section{Competing interests None declared.}

Patient consent Detail has been removed from this case description/these case descriptions to ensure anonymity. The editors and reviewers have seen the detailed information available and are satisfied that the information backs up the case the authors are making.

Ethics approval The Regional Ethical Committee and the Data Inspectorate at Oslo University Hospital in Norway approved the study.

Provenance and peer review Not commissioned; externally peer reviewed. Data sharing statement No unpublished data are available from this study.

(c) Article author(s) (or their employer(s) unless otherwise stated in the text of the article) 2018. All rights reserved. No commercial use is permitted unless otherwise expressly granted.

\section{REFERENCES}

1 Gillquist J, Messner K. Anterior cruciate ligament reconstruction and the long-term incidence of gonarthrosis. Sports Med 1999;27:143-56.

2 Lohmander LS, Englund PM, Dahl LL, et al. The long-term consequence of anterior cruciate ligament and meniscus injuries: osteoarthritis. Am J Sports Med 2007;35:1756-69.

3 Øiestad BE, Engebretsen L, Storheim K, et al. Knee osteoarthritis after anterior cruciate ligament injury: a systematic review. Am J Sports Med 2009;37:1434-43.

4 Chaudhari AM, Briant PL, Bevill SL, et al. Knee kinematics, cartilage morphology, and osteoarthritis after ACL injury. Med Sci Sports Exerc 2008;40:215-22.

5 Anderson DD, Chubinskaya S, Guilak F, et al. Post-traumatic osteoarthritis: improved understanding and opportunities for early intervention. J Orthop Res 2011:29:802-9.

6 Riordan EA, Little C, Hunter D. Pathogenesis of post-traumatic OA with a view to intervention. Best Pract Res Clin Rheumatol 2014:28:17-30.

7 Dare D, Rodeo S. Mechanisms of post-traumatic osteoarthritis after ACL injury. Curr Rheumatol Rep 2014;16:448.

8 van Meer BL, Meuffels DE, van Eijsden WA, et al. Which determinants predict tibiofemoral and patellofemoral osteoarthritis after anterior cruciate ligament injury? A systematic review. Br J Sports Med 2015:49:975-83.

9 Øiestad BE, Holm I, Gunderson R, et al. Quadriceps muscle weakness after anterior cruciate ligament reconstruction: a risk factor for knee osteoarthritis? Arthritis Care Res 2010;62:1706-14.

10 Keays SL, Newcombe PA, Bullock-Saxton JE, et al. Factors involved in the development of osteoarthritis after anterior cruciate ligament surgery. Am I Sports Med 2010;38:455-63.

11 Beynnon BD, Vacek PM, Newell MK, et al. The Effects of Level of Competition, Sport, and Sex on the Incidence of First-Time Noncontact Anterior Cruciate Ligament Injury. Am J Sports Med 2014:42:1806-12.

12 Paxinos O, Karavasili A, Delimpasis G, et al. Prevalence of Knee Osteoarthritis in 100 Athletically Active Veteran Soccer Players Compared With a Matched Group of 100 Military Personnel. Am J Sports Med 2016;44:1447-54.

13 Culvenor AG, Crossley KM. Accelerated return to sport after anterior cruciate ligament injury: a risk factor for early knee osteoarthritis? Br I Sports Med 2016;50:260-1.

14 Ajuied A, Wong F, Smith C, et al. Anterior cruciate ligament injury and radiologic progression of knee osteoarthritis: a systematic review and meta-analysis. Am I Sports Med 2014;42:2242-52.

15 Lai CCH, Ardern CL, Feller JA, et al. Eighty-three per cent of elite athletes return to preinjury sport after anterior cruciate ligament reconstruction: a systematic review with meta-analysis of return to sport rates, graft rupture rates and performance outcomes. Br J Sports Med 2018;52.

16 Hamrin Senorski E, Samuelsson K, Thomeé C, et al. Return to knee-strenuous sport after anterior cruciate ligament reconstruction: a report from a rehabilitation outcome registry of patient characteristics. Knee Surgery, Sports Traumatology, Arthroscopy 2017;25:1364-74.

17 Ardern CL, Webster KE, Taylor NF, et al. Return to sport following anterior cruciate ligament reconstruction surgery: a systematic review and meta-analysis of the state of play. Br J Sports Med 2011;45:596-606.
What are the findings?

Participants with $\mathrm{ACL}$ reconstruction (ACLR) who returned to pivoting sport had lower odds of symptomatic and radiographic osteoarthritis (OA) after 15 years.

- Participants who returned to pivoting sport were younger and had better self-reported knee function in the early phase post-ACLR.

\section{How might it impact on clinical practice in the future?}

Young athletes with ACLR should regain good knee function before they return to pivoting sport.

- Returning to pivoting sport after ACLR may not harm knee health in the long term for those with adequate knee function in the early phase.

18 Aune AK, Holm I, Risberg MA, et al. Four-strand hamstring tendon autograft compared with patellar tendon-bone autograft for anterior cruciate ligament reconstruction. A randomized study with two-year follow-up. Am J Sports Med 2001;29:722-8

19 Holm I, Oiestad BE, Risberg MA, et al. No differences in prevalence of osteoarthritis or function after open versus endoscopic technique for anterior cruciate ligament reconstruction: 12-year follow-up report of a randomized controlled trial. Am J Sports Med 2012:40:2492-8.

20 Risberg MA, Holm I, Steen $\mathrm{H}$, et al. The effect of knee bracing after anterior cruciate ligament reconstruction. A prospective, randomized study with two years' follow-up. Am J Sports Med 1999:27:76-83.

21 Risberg MA, Holm I, Tjomsland 0, et al. Prospective study of changes in impairments and disabilities after anterior cruciate ligament reconstruction. J Orthop Sports Phys Ther 1999;29:400-12.

22 Risberg MA, Holm I, Steen $\mathrm{H}$, et al. Sensitivity to changes over time for the IKDC form, the Lysholm score, and the cincinnati knee score. A prospective study of $120 \mathrm{ACL}$ reconstructed patients with a 2-year follow-up. Knee Surg Sports Traumatol Arthrosc 1999:7:152-9.

23 Oiestad BE, Holm I, Aune AK, et al. Knee function and prevalence of knee osteoarthritis after anterior cruciate ligament reconstruction: a prospective study with 10 to 15 years of follow-up. Am J Sports Med 2010;38:2201-10.

24 Risberg MA, Oiestad BE, Gunderson R, et al. Changes in knee osteoarthritis, symptoms, and function after anterior cruciate ligament reconstruction: a 20-Year prospective follow-up study. Am J Sports Med 2016:44:1215-24.

25 Holm I, Oiestad BE, Risberg MA, et al. No difference in knee function or prevalence of osteoarthritis after reconstruction of the anterior cruciate ligament with 4-strand hamstring autograft versus patellar tendon-bone autograft: a randomized study with 10-year follow-up. Am J Sports Med 2010;38:448-54.

26 Hefti F, Müller W, Jakob RP, et al. Evaluation of knee ligament injuries with the IKDC form. Knee Surg Sports Traumatol Arthrosc 1993;1:226-34.

27 Kothari M, Guermazi A, von Ingersleben G, et al. Fixed-flexion radiography of the knee provides reproducible joint space width measurements in osteoarthritis. Eur Radiol 2004:14:1568-73.

28 Roux CH, Saraux A, Mazieres B, et al. Screening for hip and knee osteoarthritis in the general population: predictive value of a questionnaire and prevalence estimates. Ann Rheum Dis 2008;67:1406-11.

29 Roos EM, Roos HP, Ekdahl C, et al. Knee injury and Osteoarthritis Outcome Score (KOOS)--validation of a Swedish version. Scand J Med Sci Sports 1998;8:439-48.

30 Noyes FR, Barber SD, Mooar LA. A rationale for assessing sports activity levels and limitations in knee disorders. Clin Orthop Relat Res 1989;246:238???249-49.

31 Tegner Y, Lysholm J. Rating systems in the evaluation of knee ligament injuries. Clin Orthop Relat Res 1985:198:42???49-9.

32 Oiestad BE, Holm I, Engebretsen L, et al. The association between radiographic knee osteoarthritis and knee symptoms, function and quality of life 10-15 years after anterior cruciate ligament reconstruction. Br J Sports Med 2011;45:583-8.

33 Sonesson S, Kvist J, Ardern C, et al. Psychological factors are important to return to pre-injury sport activity after anterior cruciate ligament reconstruction: expect and motivate to satisfy. Knee Surg Sports Traumatol Arthrosc 2017:25.

34 Ardern CL, Taylor NF, Feller JA, et al. Return-to-sport outcomes at 2 to 7 years after anterior cruciate ligament reconstruction surgery. Am J Sports Med 2012;40:41-8.

35 Ardern CL, Bizzini M, Bahr R. It is time for consensus on return to play after injury: five key questions. Br J Sports Med 2016;50:506-8. 
36 Fältström A, Hägglund M, Kvist J. Factors associated with playing football after anterior cruciate ligament reconstruction in female football players. Scand J Med Sci Sports 2016:26:1343-52.

37 Hamrin Senorski E, Samuelsson K, Thomeé C, et al. Return to knee-strenuous sport after anterior cruciate ligament reconstruction: a report from a rehabilitation outcome registry of patient characteristics. Knee Surg Sports Traumatol Arthrosc 2017;25.

38 Risberg MA, Grindem H, Øiestad BE. We Need to Implement Current Evidence in Early Rehabilitation Programs to Improve Long-Term Outcome After Anterior Cruciate Ligament Injury. J Orthop Sports Phys Ther 2016;46:710-3.

39 Filbay SR, Ackerman IN, Russell TG, et al. Return to sport matters-longer-term quality of life after ACL reconstruction in people with knee difficulties. Scand J Med Sci Sports 2017;27.
40 Ardern CL, Glasgow P, Schneiders A, et al. 2016 Consensus statement on return to sport from the First World Congress in Sports Physical Therapy, Bern. Br J Sports Med 2016;50:853-64.

41 Ardern CL, Taylor NF, Feller JA, et al. Fifty-five per cent return to competitive sport following anterior cruciate ligament reconstruction surgery: an updated systematic review and meta-analysis including aspects of physical functioning and contextual factors. Br J Sports Med 2014;48:1543-52.

42 Grindem H, Eitzen I, Moksnes H, et al. A pair-matched comparison of return to pivoting sports at 1 year in anterior cruciate ligament-injured patients after a nonoperative versus an operative treatment course. Am J Sports Med 2012;40:2509-16

43 Lentz TA, Zeppieri G, George SZ, et al. Comparison of physical impairment, functional, and psychosocial measures based on fear of reinjury/lack of confidence and return-tosport status after ACL reconstruction. Am J Sports Med 2015;43:345-53. 